\title{
Current Direct Control Simulation of Tri-level SVG Based on the Instantaneous Reactive Power Theory
}

\author{
Zhengrong Jiang ${ }^{1, a}$, Hesong Liu ${ }^{2, b}$ \\ ${ }^{1}$ College of Electrical and Control Engineering, North China University of Technology, Beijing, \\ 100144, China \\ ${ }^{2}$ College of Electrical and Control Engineering, North China University of Technology, Beijing, \\ 100144, China \\ a18801042267@163.com
}

Keywords: reactive power compensation, static var generator, reactive current detection, current direct control.

Abstract. In the design and operation in the field of ac power, reactive power is an important factor to consider. Reactive power in the power generation, transmission and distribution of three parties is extremely important, and it is also very important for the normal operation of the load. Based on SVG basic working principle, main circuit topology structure is introduced, focusing on the extraction methods of reactive current and direct current control strategy is studied. According to this theory, the use of MATLAB/Simulink to build the simulation model of SVG, and the different nature load simulation experiments, verified the control strategy is correct and fast SVG reactive power compensation capacity.

\section{Introduction}

Studying on reactive power compensation is very important, for the role of reactive power compensation is mainly summarized as follows:

i) Stability of receiving end and the voltage of power grid, improve the quality of power supply.

ii) Improving power factor of power system and the user load, reduce the equipment capacity, reducing the power loss.

iii) To avoid voltage collapse and a large area blackout of power accidents, improve operation safety.

iv) To reduce the heating of the equipment, prolong the service life of the equipment, improve equipment utilization[1].

\section{Basic principle of SVG}

The working principle is the self-commutated power semiconductor bridge circuit by connecting the reactor in parallel with the grid or in parallel with the grid, by adjusting the amplitude and phase of self-commutated bridge circuit of AC voltage or on AC side directly controlling the circuit current, can make the circuit output or absorb the required reactive current, so as to achieve the purpose of dynamic reactive power compensation[2].

\section{SVG control system}

\subsection{Reactive current real-time detection method.}

This article adopts the ip-iq operation method to test the reactive current. Because the operation

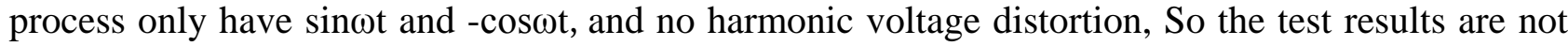
affected by the voltage waveform distortion[3]. As shown in Figure1. 


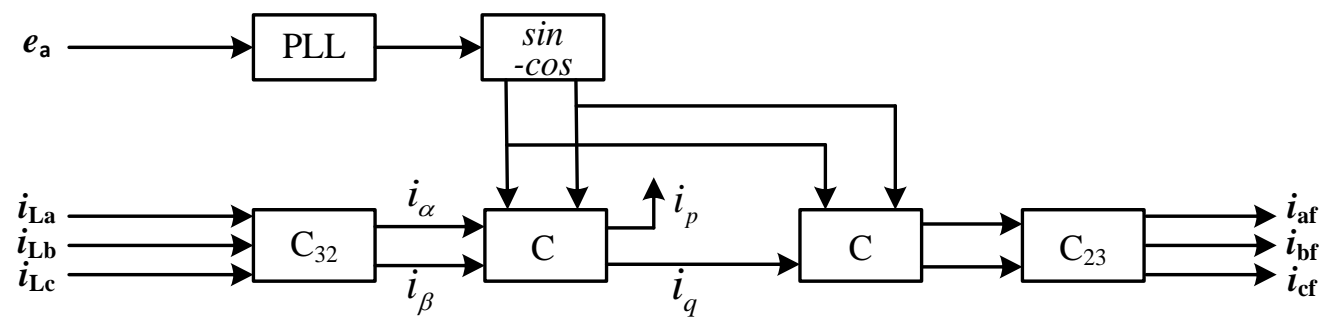

Fig.1: ip-iq operation method

The main steps are as follows:

Step1: Capture A phase voltage, and through a phase locked loop to get the phase of A phase voltage, and get the sine signal and cosine signal with A phaes voltage.

Step2: Three phase current obtained from load side power system value, and through vector transform, transform three-phase values into $\alpha-\beta$ two phase value of the coordinates.

Step3: The instantaneous reactive current through a series of inverse transform three-phase fundamental reactive current.

\subsection{Direct current control method.}

The basic idea is through the adoption of PWM control strategy of the system to treat the instantaneous reactive current to get PWM pulse signal. The signal is used as the driving signal to drive the converter controlled power electronic devices of the gate, to control the output current of the converter ac SVG instantaneous value and system of reactive power current instantaneous value keep in allowable deviation range[4].

Figure 2 is Schematic diagram of constant frequency triangle wave comparison method. The instantaneous reactive power current reference value and the SVG ac side output feedback current to compare, the operational amplifier with proportional and integral characteristics, and then compared with the triangular wave, and determine the electric power switch is open or shut off[5].

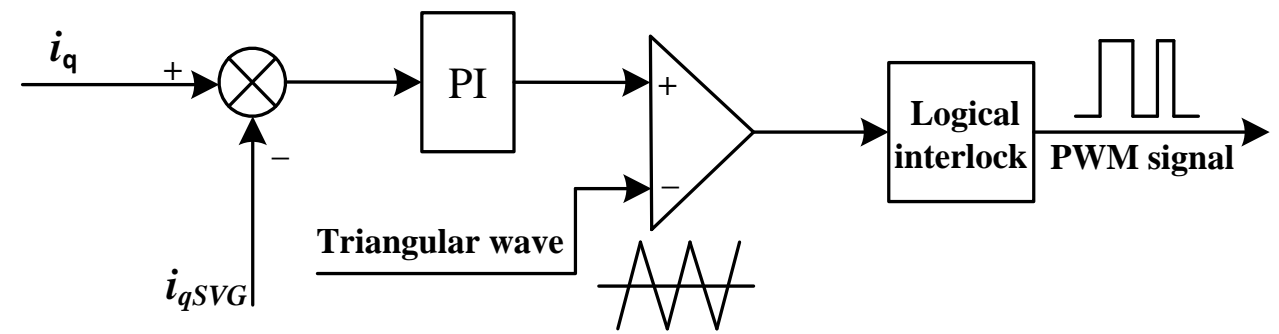

Fig.2: Triangle wave comparison method

\section{SVG system simulation}

\subsection{The establishment of SVG system simulation model.}

i) Power supply and load module

Three of the power supply module is ac voltage source.

There are two kinds of different load settings, one is RL load, the other one is RC load. They are used for simulation verify the SVG can compensate reactive power characteristics of two kinds of properties.

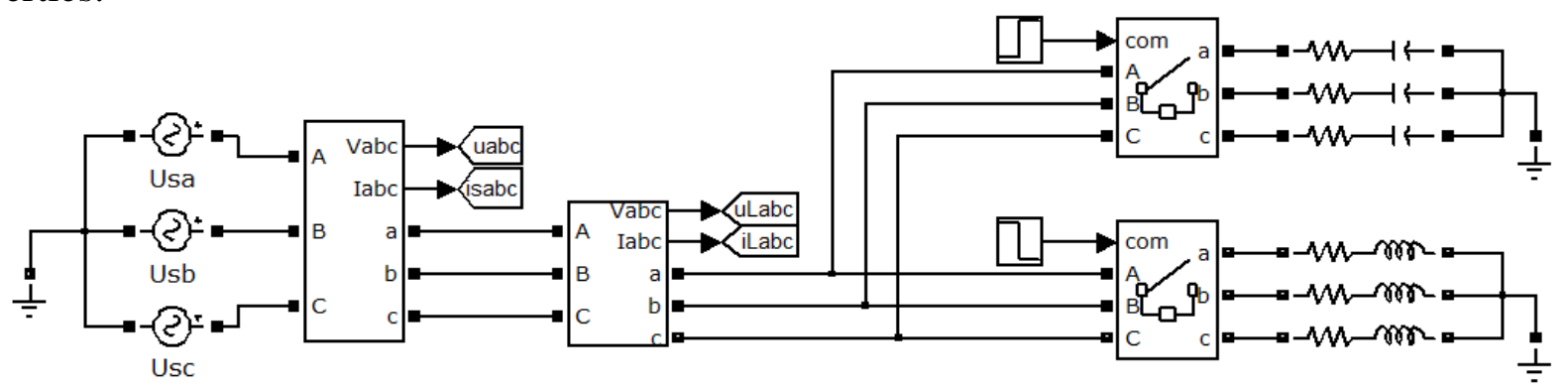

Fig.3: Power supply and load simulation module 
iii) Reactive current detection module

Input signal is respectively, instantaneous three-phase load current and dc side voltage and instantaneous voltage of three-phase power. Sine and cosine signal with the same frequency is obtained from the a phase voltage of phase lock loop. Reactive component of the three-phase load current through a series of operations to get the load current, including the control of DC side capacitor voltage. As shown in Figure 6.

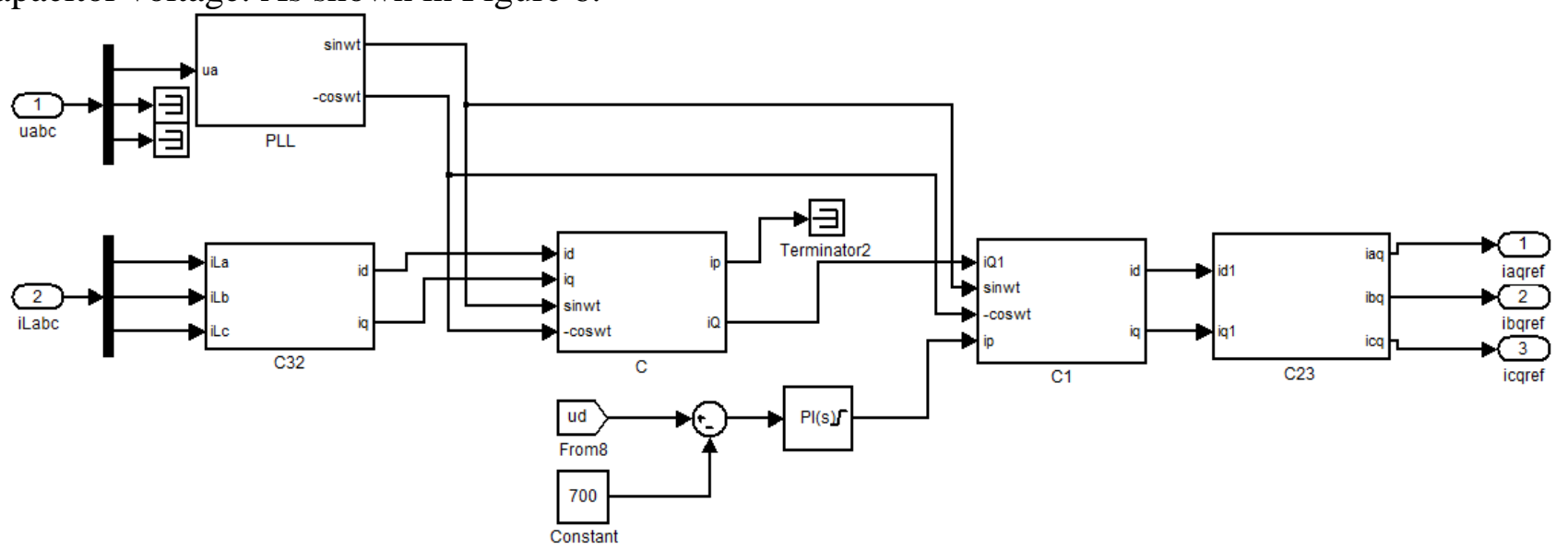

Fig.4: Reactive current detection module

iv) PWM signal generation module

This module uses triangle wave comparison method, SVG ac output current as feedback value and reactive current detection module for reactive current compare to PI regulator, and the parameters of the proportional and integral reasonable setting to trigger the gate signal of the main circuit, is used to trigger the on-off of IGBT. As shown in Figure 5.

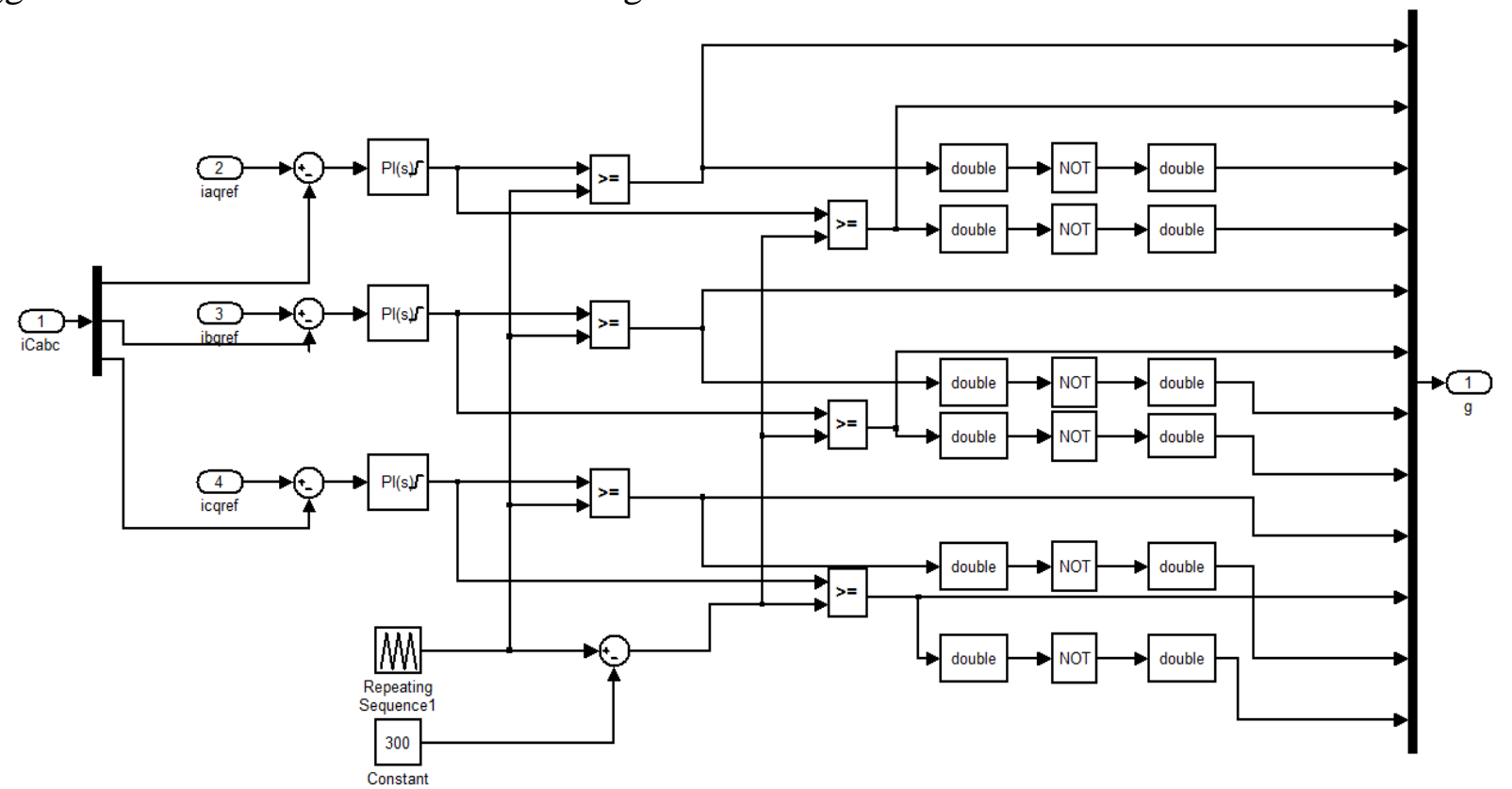

Fig.5: PWM signal generation module

\subsection{The simulation results and analysis.}

In order to reactive power dynamic compensation performance can be more comprehensive verification of SVG, this paper set up four different load conditions. 
Table 1: Setting parameters of simulation system

\begin{tabular}{lccc}
\hline Grid voltage $220 \mathrm{~V}$ & & Power system frequency \\
& & $50 \mathrm{~Hz}$ & \\
\hline Inductance $10 \mathrm{mH}$ & & Switching frequency \\
& & $8 \mathrm{kHz}$ & \\
DC side voltage $700 \mathrm{~V}$ & & DC side capacitor \\
\hline
\end{tabular}

i) Compensation for reactive power

The load is inductive load. The resistance value is $15 \Omega$. The inductance value is $0.2 \mathrm{H}$. The system current lags behind the voltage phase angle are $76.6^{\circ}$. The power factor of system is 0.23 .

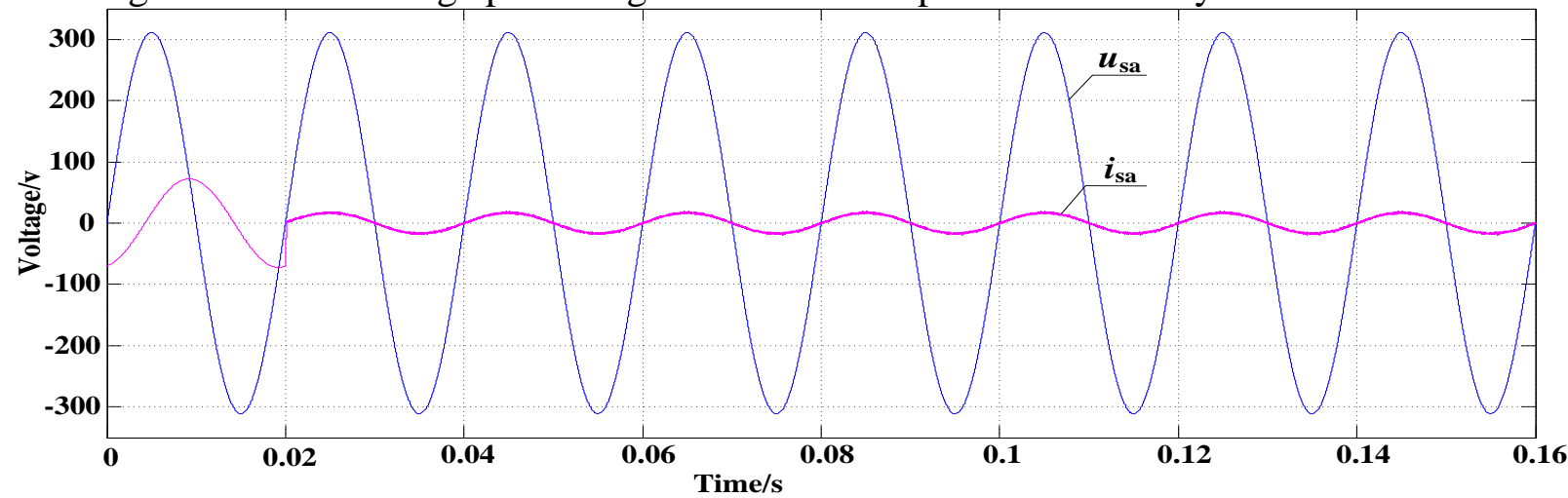

Fig.6: A phase voltage and current waveform

As can be seen from the figure, because the load is inductive, the current lags behind the voltage 76.6 $6^{\circ}$. 0.02s inputs SVG, after 0.0001s transition, phase voltage and current tends to be uniform, power factor close to 1 , while the amplitude of the system current is reduced before inputting SVG.

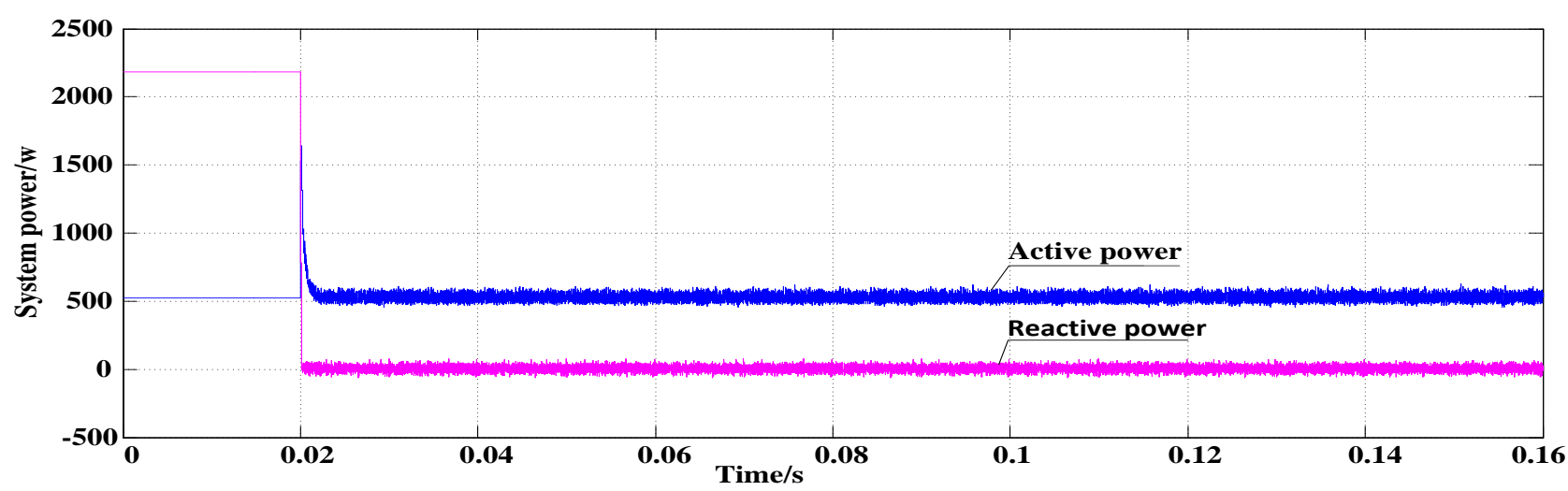

Fig.7:Curves of system active power and reactive power

As can be seen from the figure, not in the SVG runtime, power supplied to the load reactive power compensation. After $0.02 \mathrm{~s}$ in SVG, reactive power reduced to zero. 


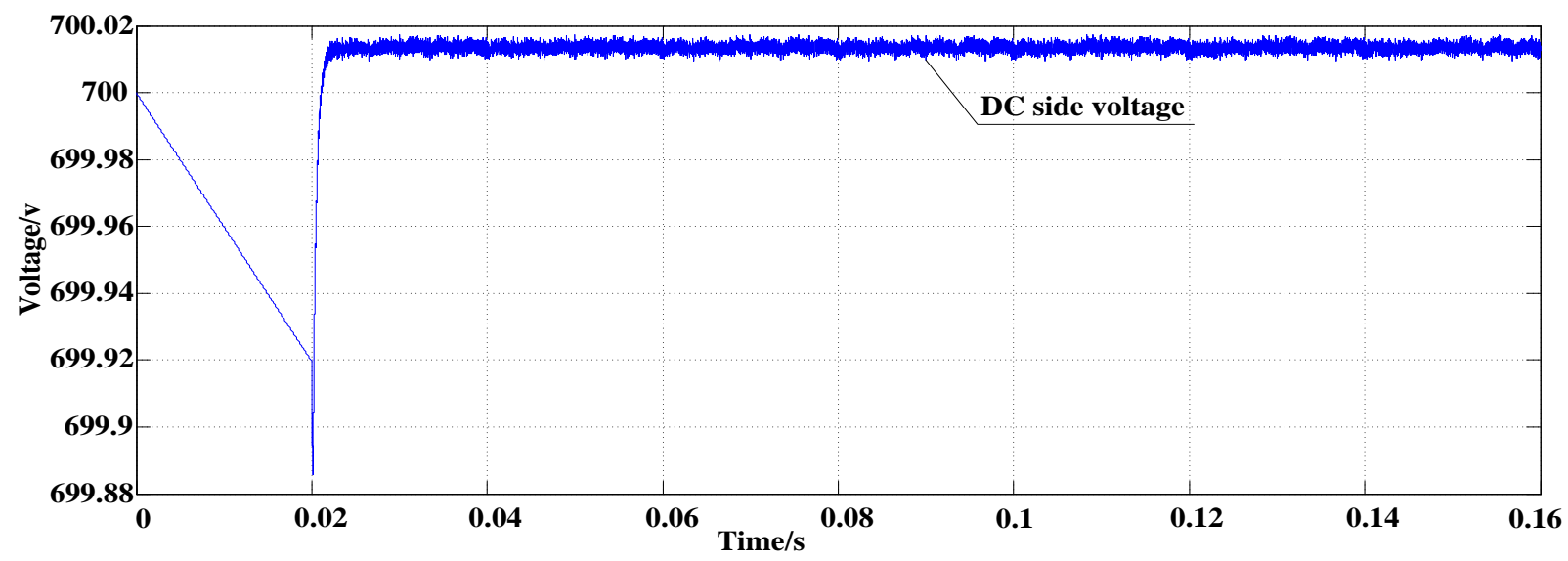

Fig.8: DC side capacitor voltage curve

As can be seen from the figure, after the $0.0001 \mathrm{~s}$, DC capacitor voltage is stable at $700.01 \mathrm{~V}$.

ii) Compensation for capacitive reactive power

Load is capacitive load. The resistance value is $15 \Omega$; The capacitance value is $100 \mu \mathrm{F}$. The system of current advanced voltage phase is $64.7^{\circ}$. The power factor of system is 0.43 .

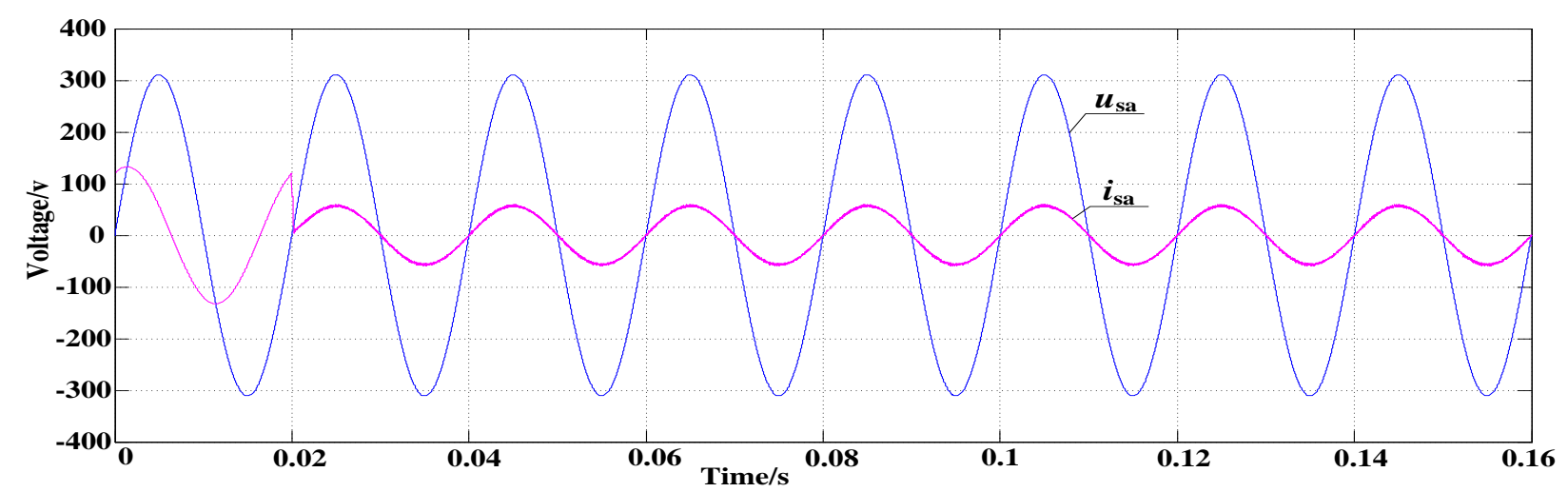

Fig.9: A phase voltage and current waveform

As can be seen from the figure, due to the load for capacitive loads, current ahead of voltage $64.7^{\circ}$; $0.02 \mathrm{~s}$ SVG into the power grid operation, after $0.00025 \mathrm{~s}$ transition, the system voltage and current phase synchronized, namely the power factor of system is close to 1 .

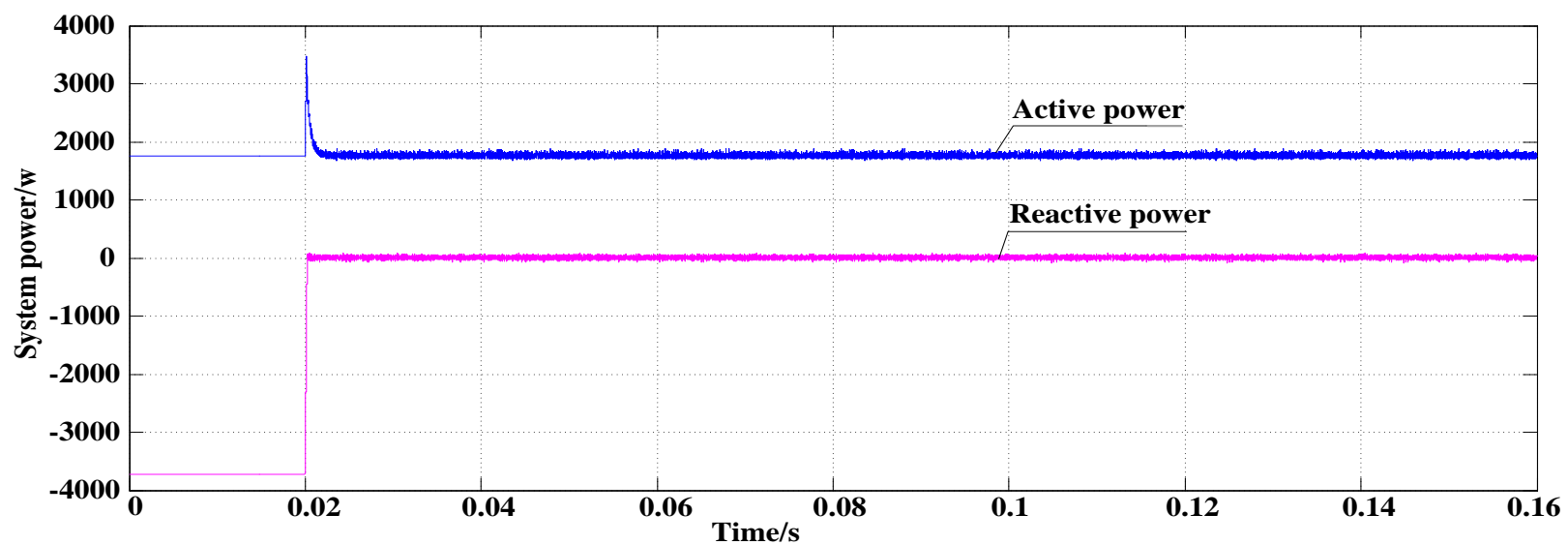

Fig.10: curves of system active power and reactive power

As can be seen from the figure, not in SVG runtime, grid provides capacitive reactive power to the load. After $0.02 \mathrm{~s}$, the value of reactive power converges to zero. 


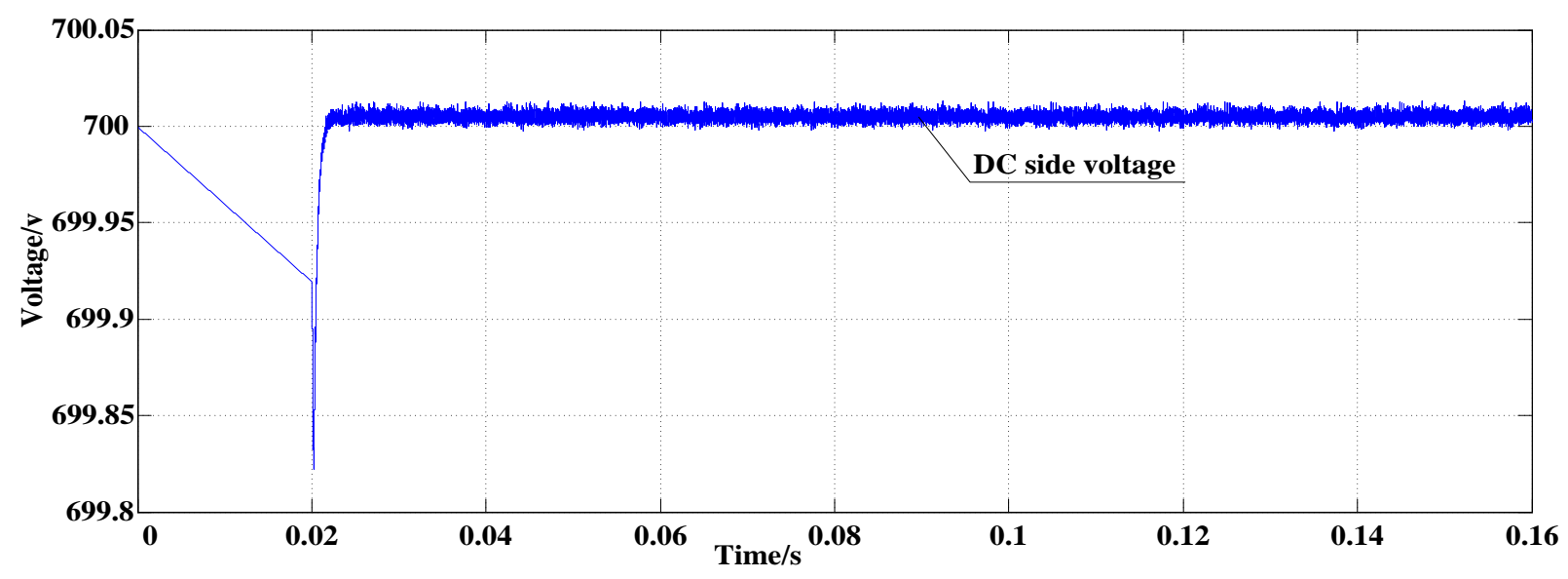

Fig.11: DC side capacitor voltage curve

As can be seen from the figure, after the $0.00015 \mathrm{~s}$, DC capacitor voltage is stable at $700.005 \mathrm{~V}$.

\section{Summary}

Using ip-iq reactive current detection method and direct current control method of SVG, the simulation results showed that SVG can effectively compensate the inductive reactive power, and can effectively compensate the capacitive reactive power. And have good dynamic compensation effect and dynamic tracking performance.

\section{Acknowledgements}

This work was financially supported by the National Natural Science Foundation (51377006) and Beijing Natural Science Foundation (3132008).

\section{References}

[1] Wang Zhaoan, Yang Jun. The harmonic suppression and reactive power compensation. Beijing: Mechanical Industry Press, 2005.

[2] Li, Haskew S, Hong T A, et al. Direct-current vector control of three-phase grid-connected rectifier-inverter. Electric Power Systems Research, 81(2):pp.357-366,2011.

[3] Xiao Juan B. Design of Control System for SVG Based on DSP TMS320F2812. Electrical Engineering, 2007.

[4] Shi Zonglin. Static var generator reactive current detection and control strategy research. Liaoning University of Technology, 2014.

[5] Junjie Liu, Zhao Gang, Li Biao. A new direct current control strategy is simulated with SVG. power system and clean energy, 27 (6),pp.21-24,2011. 